\title{
The Mayo Clinic Study of Aging: Design and Sampling, Participation, Baseline Measures and Sample Characteristics
}

\author{
Rosebud O. Roberts ${ }^{a}$ Yonas E. Geda ${ }^{a}$ d David S. Knopman ${ }^{c}$ Ruth H. Cha ${ }^{\text {b }}$ \\ V. Shane Pankratz ${ }^{b}$ Bradley F. Boeve ${ }^{c}$ Robert J. Ivnik ${ }^{d}$ Eric G. Tangalos ${ }^{e}$ \\ Ronald C. Petersen ${ }^{a, c}$ Walter A. Rocca ${ }^{a, c}$ \\ Divisions of a Epidemiology and biostatistics, Department of Health Sciences Research, and Departments of \\ 'Neurology, dPsychiatry and Psychology, and ePrimary Care Internal Medicine, College of Medicine, Mayo Clinic, \\ Rochester, Minn., USA
}

\section{Key Words \\ Cognitive impairment $\cdot$ Prevalence $\cdot$ Incidence $\cdot$ Risk \\ factors $\cdot$ Cohort studies $\cdot$ Data collection instruments}

\begin{abstract}
Background: The objective of this study was to establish a prospective population-based cohort to investigate the prevalence, incidence and risk factors for mild cognitive impairment $(\mathrm{MCl})$ and dementia. Methods: The Olmsted County, Minn., population, aged 70-89 years on October 1, 2004, was enumerated using the Rochester Epidemiology Project. Eligible subjects were randomly selected and invited to participate. Participants underwent a comprehensive in-person evaluation including the Clinical Dementia Rating Scale, a neurological evaluation and neuropsychological testing. A consensus diagnosis of normal cognition, $\mathrm{MCl}$ or dementia was made by a panel using previously published criteria. A subsample of subjects was studied via telephone interview. Results: Four hundred and two subjects with dementia were identified from a detailed review of their medical records but were not contacted. At baseline, we successfully evaluated 703 women aged $70-79$ years, 769 women aged $80-89$ years, 730 men aged $70-79$ years and 517 men aged $80-89$ years (total $n=2,719$ ). Among the participants, 2,050 subjects were
\end{abstract}

\section{KARGER}

(c) 2008 S. Karger AG, Basel

Fax +41613061234

E-Mail karger@karger.ch

www.karger.com
Accessible online at:

www.karger.com/ned evaluated in person and 669 via telephone. Conclusions: Strengths of the study are that the subjects were randomly selected from a defined population, the majority of the subjects were examined in person, and $\mathrm{MCl}$ was defined using published criteria. Here, we report the design and sampling, participation, baseline measures and sample characteristics.

Copyright $\odot 2008$ S. Karger AG, Basel

\section{Introduction}

The overall prevalence of dementia doubles every 5 years from approximately $1 \%$ in persons aged $60-65$ years to $45 \%$ in persons aged $90-95$ years [1-3]. Similarly, the incidence rate of dementia rises steeply with increasing age from $<1 \%$ per year in 65 - to 69 -year-olds to nearly $14 \%$ per year in persons aged $\geq 85$ years $[4,5]$. Dementia, including its most common type Alzheimer's disease (AD), is an important cause of morbidity, nursing home placement and mortality. Additionally, the aging of the United States population in recent decades has resulted in an increasing number of elderly persons with dementia and $\mathrm{AD}$. Yet, a major problem with $\mathrm{AD}$ is the lack of curative treatment. Therefore, an important means of re-
Dr. Rosebud O. Roberts

Division of Epidemiology, Department of Health Sciences Research

Mayo Clinic, 200 First Street SW

Rochester, MN 55905 (USA)

Tel. +1 507284 5656, Fax +1 507284 1516, E-Mail roberts.rosebud@mayo.edu 
ducing the public health burden of AD and other dementias is the early detection of a treatable prodromal or preclinical phase. Mild cognitive impairment (MCI) may represent such a transitional stage between normal aging and $\mathrm{AD}[6]$.

The Mayo Clinic Study of Aging was designed to establish a prospective population-based cohort of subjects to study prevalence, incidence and risk factors for MCI and dementia. Here, we describe the design and sampling, participation, baseline measures and sample characteristics of the study.

\section{Study Methods}

\section{Objectives}

The objectives of the Mayo Clinic Study of Aging were to determine in the population of Olmsted County, Minn., (1) the prevalence of MCI; (2) the incidence of MCI; (3) conversion rates from MCI to dementia or AD; (4) risk factors for MCI; and (5) risk factors for the progression from MCI to dementia or AD.

\section{Design and Methods}

Study Setting

The study was conducted in Olmsted County, where several factors enhance the feasibility of population-based epidemiologic research. Most residents seek care within the community from essentially 2 providers, the Mayo Clinic and Olmsted Medical Center, along with their affiliated hospitals and medical facilities within the county. Both healthcare providers use a unit medical record which includes all outpatient and inpatient information for each patient. Furthermore, medical record information from all medical care providers to county residents can be easily retrieved using patient identifiers through the records-linkage system of the Rochester Epidemiology Project, an extensive indexing system based on surgical and medical diagnoses maintained by the Mayo Clinic [7]. This records-linkage system also permits researchers to generate a list of all county residents on a given date [7].

Study Design and Sampling Frame

We used the medical records-linkage system to construct a sampling frame of Olmsted County residents aged $70-89$ on October 1, 2004, who had been in contact with the system at least once within the 3 years prior to the index date $(n=20,805)$. Duplicate records for the same persons were identified and excluded by searching for duplicate matching birth date and names, social security numbers and clinical identifiers $(n=8,752)$; a single record was created for each resident. Addresses of residences located on the border of Olmsted County were manually checked by a nurse abstractor to exclude subjects who were nonresidents $(\mathrm{n}=2,100)$. Thus, we enumerated 9,953 unique individuals in our sampling frame (fig. 1). A comparison of the sampling list derived from the records-linkage system with the projected 2004 census counts (from a linear projection of 2000 national census data) showed that we identified $106 \%$ of the men and $99 \%$ of the women aged $70-79$ years, and $114 \%$ of men and $101 \%$ of women aged $80-89$ years [8].
Sample Size and Power Estimations

The intended sample size of the study was 2,300 persons: 550 men and 550 women aged 70-79 years, and 600 men and 600 women aged $80-89$ years. It was estimated that approximately 300 persons would have dementia at baseline, and 2,000 persons would be free of dementia [9-11]. This would provide sufficient power to prospectively ascertain incident $\mathrm{MCI}$ or $\mathrm{AD}$. Based on published estimates of MCI prevalence, we estimated that 434 recruited persons would have prevalent MCI and approximately 1,566 persons would be cognitively normal at enrollment [12]. The prevalence of MCI could be estimated with a $95 \%$ confidence interval (CI) of approximately $\pm 3.3 \%$.

Ethical Issues

All study procedures and ethical aspects were approved by the institutional review boards of the Mayo Clinic and Olmsted Medical Center. All persons examined as part of the study were informed of the scope of the project and signed an informed consent form including a Health Insurance Portability and Accountability Act (HIPAA) authorization.

\section{Recruitment Protocol}

The recruitment protocol involved the following steps: a stratified random selection of subjects from the sampling frame, a letter of invitation followed by a recruitment telephone call, and finally an in-person evaluation or a telephone assessment.

\section{Stratified Random Sampling}

Stratified sampling was performed by randomly selecting subjects from within the 4 age and sex strata of the sampling frame. Each subject was given a unique identifier and all subjects within a stratum were sorted by this identifier to define the order of contact. The Minnesota Life Tables for 2000 were used to estimate the remaining number of years of life for subjects in each of the 4 cells: 6.6 years for men aged $80-89$ years, 8.3 years for women aged $80-89$ years, 11.9 years for men aged $70-79$ years and 14.6 years for women aged 70-79 years [13]. These estimates were used to prioritize subjects for recruitment. Eligible older subjects with the least number of remaining years of life were contacted earlier.

Letter and Telephone Recruitment

The medical records of subjects selected for the study that were archived by the records-linkage system were screened to identify dementia. If a diagnosis of dementia was identified or suspected, the complete medical record was reviewed by a behavioral neurologist (D.S.K.) to confirm the diagnosis of dementia. Persons with a confirmed diagnosis of dementia were not contacted for participation. Subjects presumed to be free of dementia were sent a letter of invitation that briefly described the rationale and purpose of the study. Subjects were given the opportunity to decline participation by returning the letter of refusal in a postage-paid envelope. Two weeks after the mailing, subjects who had not mailed back a letter of refusal received a telephone call from a trained study coordinator. The telephone script briefly described the study and included an invitation to participate. A maximum of 10 phone calls were made during the day, evening, or weekend. Subjects who agreed to be seen in person were scheduled for an evaluation. Subjects who refused to be seen in person were invited to participate in a structured telephone interview. All participants were also asked to provide the name and telephone number of a 


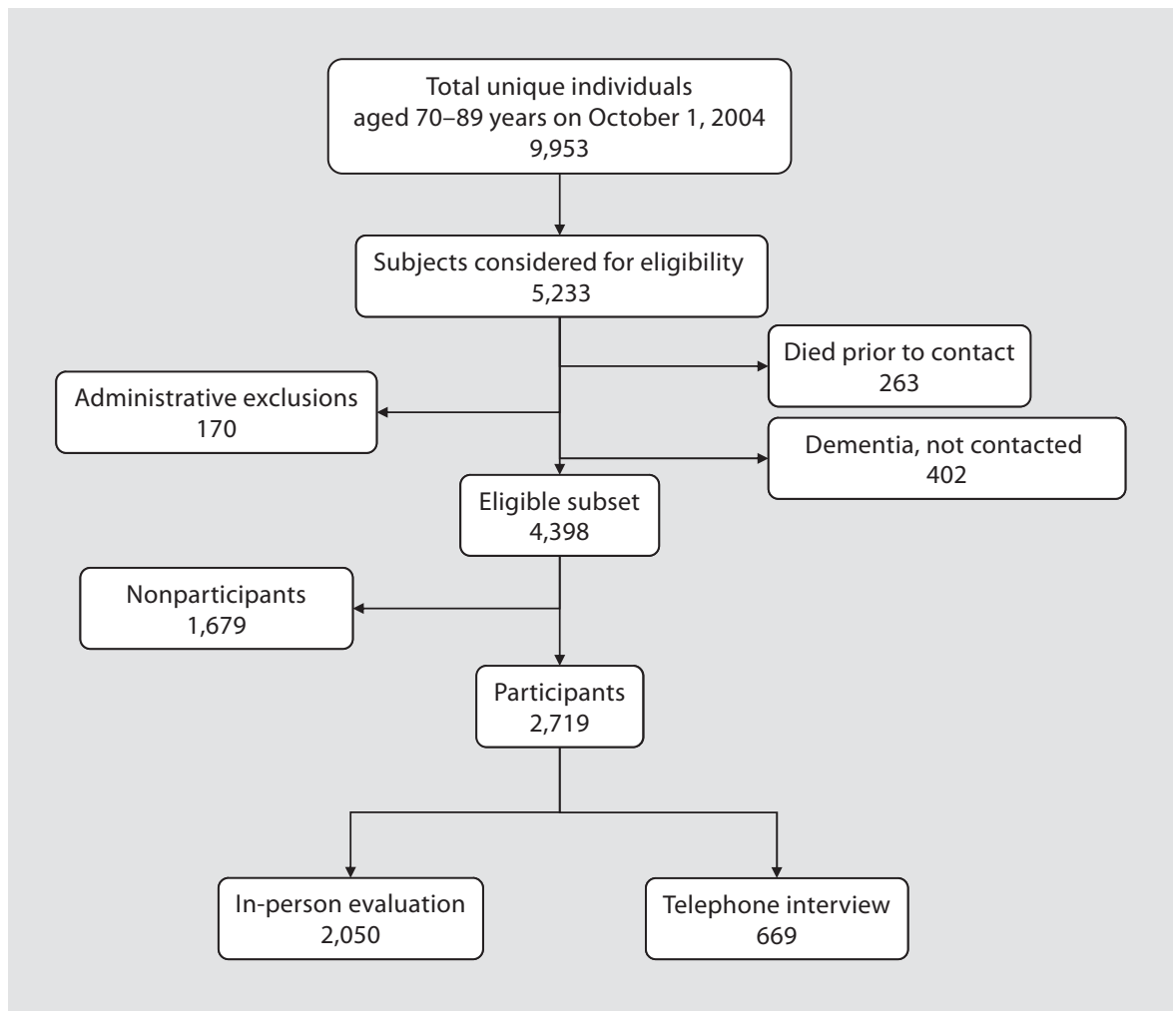

Fig. 1. Flow chart describing the steps involved in establishing the study sample from among 5,233 randomly selected Olmsted County, Minn., residents aged 70-89 years on October 1, 2004. Administrative exclusions comprise 56 people who were terminally ill or in hospice and 114 who could not be contacted to confirm eligibility.

study partner (informant). This was someone who knew them well and would be willing to answer questions about their cognition and daily functioning.

\section{Strategies to Enhance Participation}

Several strategies were employed to enhance participation in the study. A Mayo Clinic pamphlet titled 'Staying Mentally Healthy' was included with the letter of invitation as a token of appreciation. The study was advertised in the local newspaper, weekly radio advertisements were made, posters advertising the study were placed in the community, and we gave presentations on air at local radio stations, at the largest retirement complex in the county and at a local Kiwanis Club frequented by elderly persons. A free taxi service or reimbursement for transportation costs was offered. A remuneration of USD 50 was also given to the participants.

\section{Baseline Clinical Evaluation}

The in-person evaluation was performed at the Mayo Clinic Abigail Van Buren Alzheimer's Disease Research Clinic or at the place of residence of the participants using a standardized protocol (fig. 2). Subjects underwent a nurse evaluation and risk factor assessment, a neurological evaluation and a neuropsychological evaluation.

Nurse Evaluation and Risk Factor Assessment

This evaluation was performed by a nurse or a study coordinator. After signing the informed consent form, a 10-hour fasting blood draw was performed for subjects seen in the morning. Subjects scheduled for afternoon appointments were asked to eat a light breakfast and to have no food at least $4 \mathrm{~h}$ prior to the appointment. Other studies have suggested that measurement of lipids from nonfasting blood samples may yield valid results $[14,15]$. Serum and plasma samples were aliquoted, DNA was extracted, and samples were labeled and stored in a $-80^{\circ} \mathrm{C}$ freezer.

Subjects were asked to enumerate all first-degree relatives, and were questioned about past diagnoses of MCI, dementia, AD, Parkinson's disease, frontotemporal dementia and amyotrophic lateral sclerosis in these relatives. We also collected information on demographic characteristics including date of birth, marital status, education, ethnicity, residence (community living, institution), and on name and dose of all current medications (subjects were instructed to bring the bottles of current medications to the appointment). Current or previous symptoms of anxiety, depression, or alcoholism were assessed using screening instruments such as the Patient Health Questionnaire version of the PRIME MD [16], the Beck Depression Inventory [17] and the Beck Anxiety Inventory [18]. Subjects who screened positive for psychiatric symptoms were assessed further by a physician (see 'Neurological Evaluation'). The subjects also reported prior diabetes, hypertension, coronary heart disease, atrial fibrillation, stroke or transient ischemic attack, cancer, depression, cigarette smoking or tobacco use and overall well-being. Self-reported medical history was corroborated using information abstracted from the medical records of the records-linkage system. Blood pressure was measured twice using a standard sphygmomanometer, height was measured using 


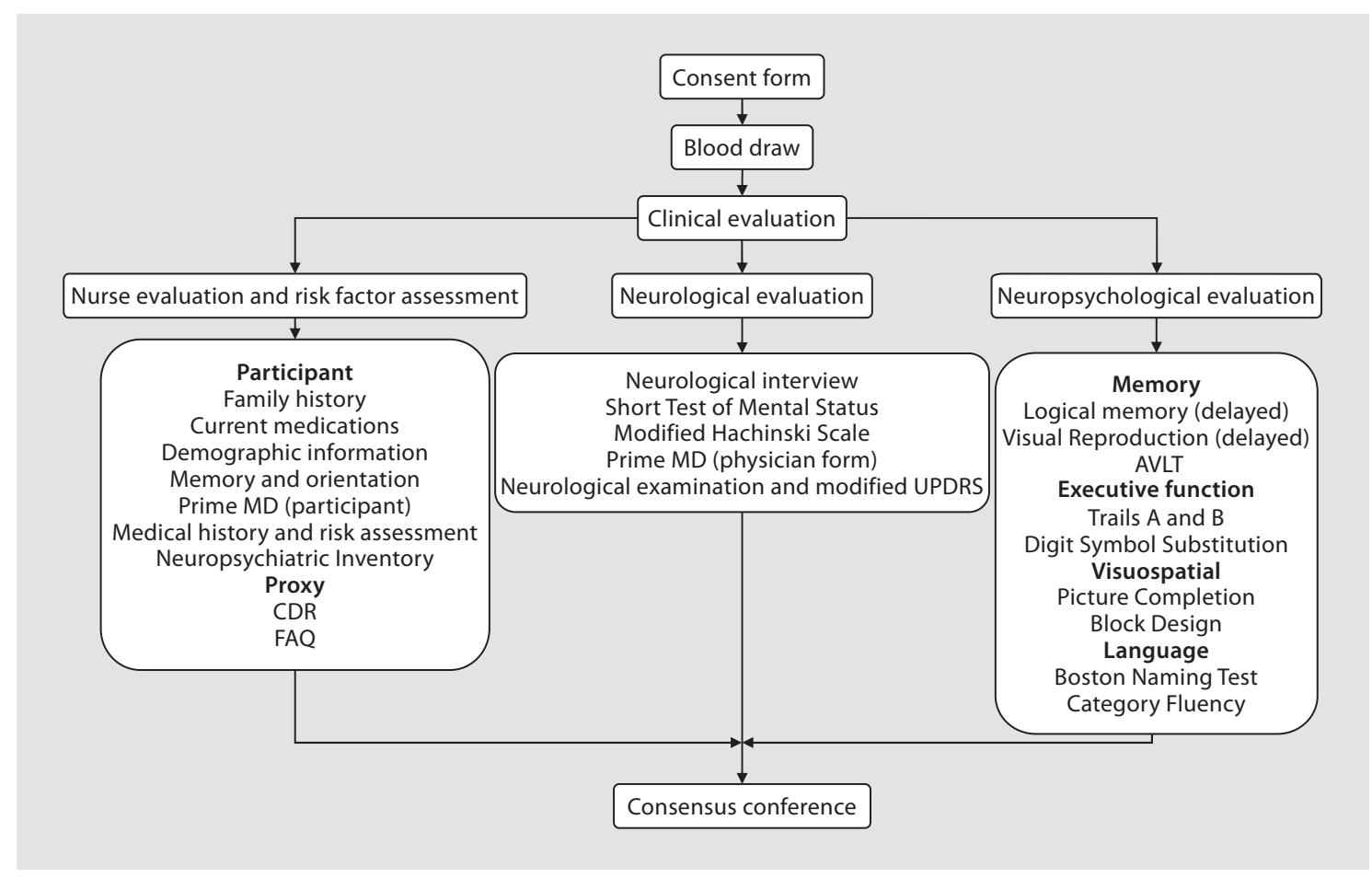

Fig. 2. Flow chart describing the protocol for in-person clinical evaluation of study participants. The evaluation included 3 components: a nurse evaluation and risk factor assessment; a neurological evaluation, and a neuropsychological evaluation. Specific measurements for each component are described. AVLT = Auditory Verbal Learning Test; UPDRS = Unified Parkinson's Disease Rating Scale; CDR = Clinical Dementia Rating; FAQ = Functional Assessment Questionnaire. a stadiometer, weight was evaluated with an electronic balance, and frailty was measured as time needed to walk 25 feet without assistance [19].

The Clinical Dementia Rating Scale (CDR) [20] was administered to a study partner (informant) to assess the cognition and functional activities of the subject. The CDR score (range $=0-3$ ) and the CDR sum of boxes (range $=0-36$ ) were assessed independently of the results of the neuropsychological testing. In addition, the functional status of each subject was elicited from the study partner also using the Functional Assessment Questionnaire (range $=0-30)[21]$.

\section{Neurological Evaluation}

The neurological evaluation was performed by a neurologist or by a physician of another specialty (geriatrics, psychiatry) who had been specifically trained for this study. The physician administered the Short Test of Mental Status [22], a modified Hachinski Scale $[23,24]$ and a questionnaire developed to elicit neurologic conditions that could influence cognition. The questionnaire assessed Parkinson's disease, depression, anxiety, alcoholism, problems with balance, tremor, speech, stroke or transient ischemic attack and sleep problems. Subjects who had screened positive for symptoms of depression, anxiety or alcoholism were further evaluated using the Clinician Evaluation Guideline component of the PRIME MD, a semistructured interview that generates Diagnostic and Statistical Manual of Mental Disorders - IV
(DSM-IV) [25] diagnoses for depressive disorders, anxiety disorders or alcohol use disorders [16]. Finally, the physician performed a neurological examination and administered a modified Unified Parkinson's Disease Rating Scale [26].

\section{Neuropsychological Evaluation}

This evaluation was performed by a psychometrist specifically trained for this study. A neuropsychological battery was designed using subtests of the Wechsler Adult Intelligence ScaleRevised (WAIS-R) [27], the Wechsler Memory Scale-Revised (WMS-R) [28] and other tests to assess 4 cognitive domains. The domains evaluated were: (1) executive function (Trail Making Test B [29] and Digit Symbol Substitution Test [27]); (2) language (Boston Naming Test [30] and Category Fluency [31]); (3) memory [Logical Memory-II (delayed recall), Visual Reproduction-II (delayed recall) [28] and Auditory Verbal Learning Test (delayed recall) [32]], and (4) visuospatial (Picture Completion and Block Design [27]). First, we transformed the raw scores on each test into age- and education-adjusted scores using Mayo's Older American Normative Studies normative data. These adjusted scores were also scaled to have a mean of 10 and a standard deviation of 3 [32]. Second, we obtained domain scores by adding the adjusted and scaled scores of the tests included within each domain. Because different numbers of tests were used to compute domain scores (i.e., 2 tests for the executive, language, and visuospatial domains versus 3 tests for memory), the domain scores 


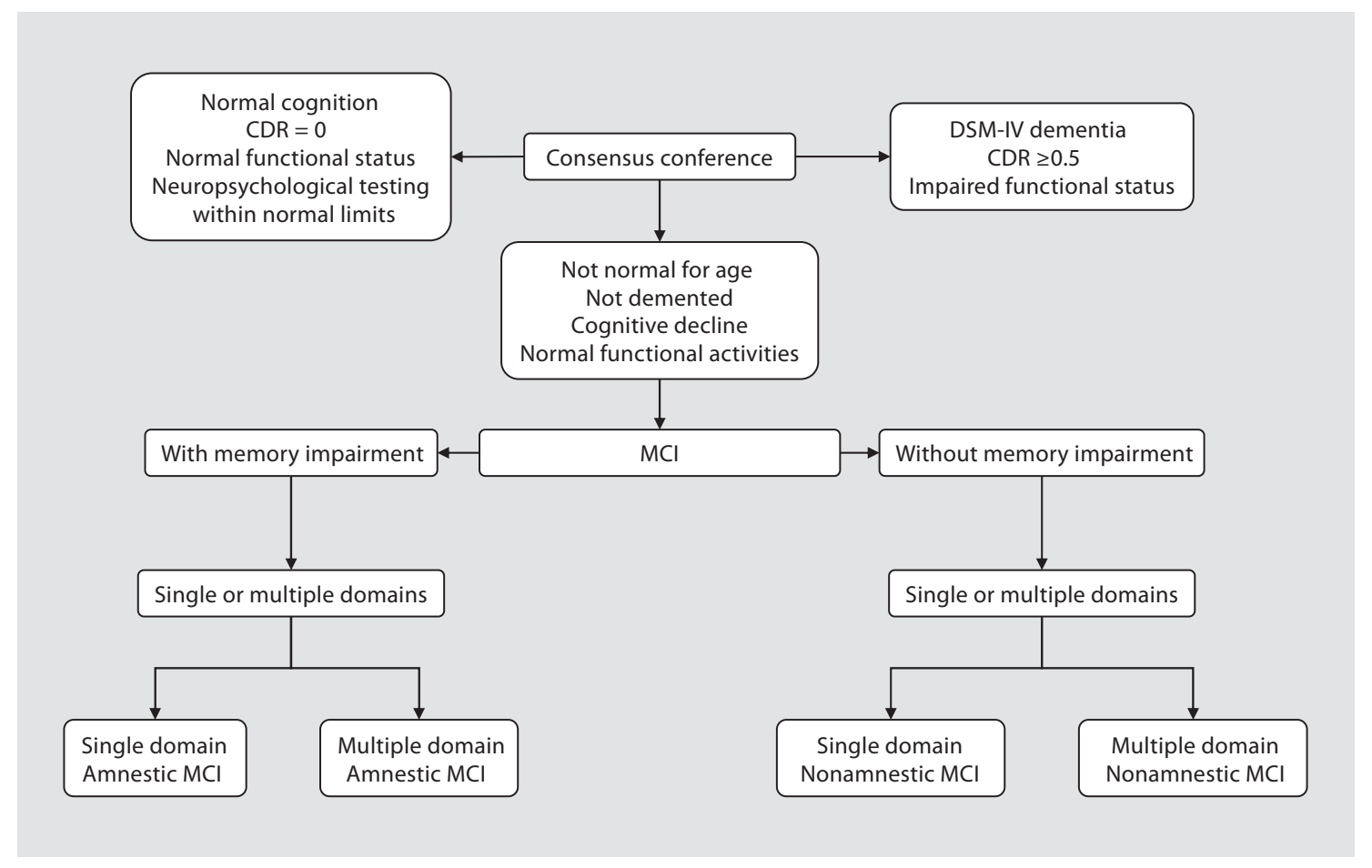

Fig. 3. Diagnostic scheme for normal cognition, MCI or dementia. CDR = Clinical Dementia Rating; DSMIV = Diagnostic and Statistical Manual of Mental Disorders - IV; MCI = mild cognitive impairment.

were also scaled to allow comparisons across domains. In summary, the performance of a person in a particular domain was measured by comparing the person's domain score with the score in normals. This approach relies on previous normative work and extensive experience with the measurement of cognitive abilities of the population from which the study participants have been drawn [32-34]. However, the final decision about impairment in any cognitive domain was ultimately made by consensus agreement between the examining neurologist, nurse and neuropsychologist taking into account education, prior occupation and other information.

\section{Diagnostic Classification for In-Person Participants}

Each study evaluator (nurse, physician or psychometrist) reached a preliminary impression of the cognitive status of the subject, independent of the impression of the other evaluators. Subsequent to the full evaluation, an expert consensus panel consisting of the study physicians, nurses and neuropsychologists reviewed and discussed all the data for each subject.

\section{Criteria for Normal Cognition or Dementia}

If persons were judged to have no cognitive impairment according to published criteria $[6,32]$ and received a CDR of 0 , they were enrolled as cognitively normal subjects. Subjects with a CDR $>1$ were classified as demented if they met DSM-IV criteria for dementia [25]. Subjects who received a CDR of 0.5 had a more intense evaluation to determine if they met criteria for MCI or for mild dementia. The consensus committee took a critical look at information from the CDR, neuropsychological testing, clinical examination and the Short Test of Mental Status [21] to determine whether the subject with a CDR of 0.5 met the DSM-IV criteria for dementia [24]. Subjects with a CDR of 0.5 who met the criteria for mild dementia are being followed over time to determine the stability of the diagnosis.

\section{Criteria for MCI}

Subjects who were neither demented nor cognitively normal were classified as having MCI according to published criteria [6]. These criteria are: cognitive concern expressed by a physician, informant, participant or nurse; cognitive impairment in $\geq 1$ domains (executive function, memory, language or visuospatial); normal functional activities; not demented. Subjects with MCI could have a CDR of 0 or 0.5 ; however, the final diagnosis of MCI was not based exclusively on the CDR but rather on all available data. They were further classified as having amnestic or nonamnestic MCI, as having single- or multiple-domain MCI (fig. 3) and according to the presumed etiology of MCI (e.g., degenerative, vascular, trauma, psychiatric). The diagnosis of normal cognition, $\mathrm{MCI}$, dementia or $\mathrm{AD}$ was made by consensus, taking into account all the data collected. If the information obtained by 1 of the 3 evaluators (nurse, physician or psychometrist) was not consistent with the final diagnosis, this was noted as discordance.

\section{Telephone Interview}

Subjects who refused the in-person evaluation were invited to participate in a structured telephone interview by trained study assistants to collect information on education, occupation, marital status and residence. The Telephone Interview for Cognitive 
Status Modified (TICS-m; 12 items; range $=0-50$ ) was administered to assess cognitive function [35-37]. The TICS-m has been reported to yield information that is of value for assessment of cognitive impairment and dementia in epidemiologic research [38]. In addition, each subject was asked to provide the name and telephone number of a study partner (informant) who knew them well and would be willing to answer questions about them. If available, the study partner was contacted by telephone and asked to rate the participant on the AD8 Dementia Screening Interview (AD8; range $=0-8)[39,40]$. The AD8 interview specifically requested that the study partner rate any change in function for each of 8 functional items. Both TICS-m and AD8 were scored according to published criteria $[35,39]$. A HIPAA form was mailed to each subject for return in an addressed and stamped envelope; subjects who did not return the first form received a second mailing. Data were used in analyses only after the subjects had provided HIPAA authorization.

\section{Quality Control}

Prior to onset of the study, the study coordinators were trained in the use of a telephone script to invite subjects by a senior study coordinator with several years of experience conducting telephone interviews for research. The telephone script was pilot-tested and modified, and the final version was used in the recruitment of study subjects. The study personnel who conducted the TICS-m and AD8 interviews were also specifically trained in the administration of the study instruments. All study nurses were trained in the use of the CDR through an online training program to ensure consistency in the administration and rating of the questionnaire (www.adrc.wustl.edu) [20]. The medical history and risk factor questionnaire used by the nurses were derived from previously validated questionnaires used in epidemiologic studies such as the Cardiovascular Health Study [41], Atherosclerosis Risk in Communities Study [42] and the Behavioral Risk Factor Surveillance System [43]. All study questionnaires were pilot-tested in 25 persons for face and content validity, comprehension and clarity. Changes were made on the basis of the pilot test to enhance understanding, flow of questions and efficiency.

Self-reported risk factors will be validated by a detailed review of the medical records from the records-linkage system for a subset of subjects. In particular, subjects selected for case-control studies nested within the cohort will undergo extensive medical record abstraction. Previous studies suggest that vascular risk factors are accurately reported in the medical record [44] with minimal missing information [45].

To assess the potential for nonparticipation bias, factors that may affect cognition (study endpoints) or participation (demographic and clinical factors) were assessed electronically through the diagnostic index of the medical records-linkage system in a comparable fashion for participants and nonparticipants. The information evaluated included years of education, vascular disease, a specific diagnosis of MCI or dementia (which had not been confirmed by the study neurologist, D.S.K.), or a notation of cognitive impairment or dysfunction. A Charlson Comorbidity Index [46] was also calculated from diagnoses assessed electronically using the records-linkage system. Medical records were reviewed for participants and for non-participants who had provided authorization for use of their medical record in research prior to the contact for the present study.

\section{Statistical Analyses}

The demographic, clinical and neuropsychological characteristics of the in-person and telephone participants are described by age and sex. Participants and nonparticipants were compared with regard to factors that could affect participation or study endpoints. The odds ratios (OR) and 95\% CIs of participation for demographic and clinical characteristics were assessed in both univariate and multivariable analyses adjusted for age, sex, and education.

\section{Results}

\section{Study Sample}

The 9,953 subjects (fig. 1) were listed in random order within age and sex strata. From among 5,233 subjects considered for eligibility, 4,398 were eligible for participation after the exclusion of 402 subjects with confirmed dementia. Subjects who were terminally ill or in hospice $(n=56)$ were considered ineligible because their condition could preclude valid assessments from study questionnaires and neurological or neuropsychological evaluations. Subjects in hospice were identified either from information provided during the initial telephone contact or from a review of the medical records. In addition, subjects who could not be contacted for verification of their eligibility to participate $(n=114)$ were also excluded (total administrative exclusions $=56+114=170$; fig. 1). Finally, subjects who were alive on October 1, 2004, but died before any contact was made $(n=263)$ were also considered ineligible (fig. 1). Of the eligible subjects, 2,050 (62\%) were evaluated in person, 669 participated by telephone interview (total $=2,719$ participants), and 1,679 either refused participation $(1,657)$ or died after the initial contact ( $n=22$, fig. 1$)$.

\section{Demographic Characteristics of the Sample}

Overall, $52.7 \%$ of the subjects were $70-79$ years old, $49.0 \%$ had $>12$ years of education, and $58.5 \%$ were married (table 1). The majority were Caucasian $(92.9 \%, \mathrm{n}=$ $2,526) ; 84.5 \%(\mathrm{n}=2,298)$ lived in their own home or apartment, $10.9 \%(\mathrm{n}=296)$ in a retirement community, $1.5 \%(\mathrm{n}=42)$ in a convent and $2.8 \%(\mathrm{n}=75)$ in an assisted living facility or a nursing home; $94.1 \%$ in-person participants were retired. In general, telephone and inperson participants were similar, but telephone participants were more likely to be women (70.3 vs. $48.9 \%$; $\mathrm{p}<$ 0.0001 ) and less likely to have $\geq 12$ years of education (40.2 vs. 51.9\%; p < 0.0001) compared with in-person participants. Over $53 \%$ of the in-person participants had a spouse and $28.6 \%$ had an offspring or in-law as an infor- 
Table 1. Demographic characteristics of in-person and telephone participants

\begin{tabular}{|c|c|c|c|c|c|c|c|c|c|c|c|c|}
\hline \multirow[t]{3}{*}{ Variable } & \multicolumn{5}{|c|}{ In-person participants } & \multicolumn{5}{|c|}{ Telephone participants } & \multirow{2}{*}{\multicolumn{2}{|c|}{$\begin{array}{l}\text { Total sample } \\
(\mathrm{n}=2,719)\end{array}$}} \\
\hline & \multicolumn{2}{|c|}{$\begin{array}{l}\text { men } \\
(\mathrm{n}=1,048)\end{array}$} & \multicolumn{2}{|c|}{$\begin{array}{l}\text { women } \\
(\mathrm{n}=1,002)\end{array}$} & \multirow{2}{*}{$\begin{array}{l}\text { all } \\
\%\end{array}$} & \multicolumn{2}{|c|}{$\begin{array}{l}\text { men } \\
(n=199)\end{array}$} & \multicolumn{2}{|c|}{$\begin{array}{l}\text { women } \\
(\mathrm{n}=470)\end{array}$} & \multirow{2}{*}{$\begin{array}{l}\text { all } \\
\%\end{array}$} & & \\
\hline & $\mathrm{n}$ & $\%$ & $\mathrm{n}$ & $\%$ & & $\mathrm{n}$ & $\%$ & $\mathrm{n}$ & $\%$ & & $\mathrm{n}$ & $\%$ \\
\hline \multicolumn{13}{|l|}{ Age } \\
\hline 70-79 years & 596 & 56.9 & 490 & 48.9 & 53.0 & 134 & 67.3 & 213 & 45.3 & 51.9 & 1,433 & 52.7 \\
\hline $80-89$ years & 452 & 43.1 & 512 & 51.1 & 47.0 & 65 & 32.7 & 257 & 54.7 & 48.1 & 1,286 & 47.3 \\
\hline \multicolumn{13}{|l|}{ Education } \\
\hline$\leq 12$ years & 496 & 47.3 & 491 & 49.0 & 48.1 & 121 & 60.8 & 279 & 59.4 & 59.8 & 1,387 & 51.0 \\
\hline$>12$ years & 552 & 52.7 & 511 & 51.0 & 51.9 & 78 & 39.2 & 191 & 40.6 & 40.2 & 1,332 & 49.0 \\
\hline \multicolumn{13}{|l|}{ Marital status } \\
\hline Married & 856 & 81.7 & 400 & 39.9 & 61.3 & 160 & 80.4 & 174 & 37.0 & 49.9 & 1,590 & 58.5 \\
\hline Other & 192 & 18.3 & 602 & 60.1 & 38.7 & 39 & 19.6 & 296 & 63.0 & 50.1 & 1,129 & 41.5 \\
\hline \multicolumn{13}{|l|}{ Informant } \\
\hline Spouse & 769 & 73.4 & 319 & 31.8 & 53.1 & 112 & 56.3 & 88 & 18.7 & 29.9 & 1,288 & 47.4 \\
\hline $\begin{array}{l}\text { Offspring, son/ } \\
\text { daughter-in-law }\end{array}$ & 166 & 15.8 & 421 & 42.0 & 28.6 & 15 & 7.5 & 71 & 15.1 & 12.9 & 673 & 24.8 \\
\hline Other & 86 & 8.2 & 232 & 23.2 & 15.5 & 7 & 3.5 & 45 & 9.6 & 7.8 & 370 & 13.6 \\
\hline
\end{tabular}

Informant: 30 women and 27 men among the in-person participants, and 266 women and 65 men among the telephone participants did not provide information on an informant. Other informant includes relatives, paid caregivers, friends and neighbors.

mant (table 1). The frequency of contact with the informant suggested that the information obtained for the CDR was accurate; $69.2 \%$ of the informants for women and $88.0 \%$ of the informants for men reported seeing the participant daily or several times a week (not assessed for telephone participants). Overall, $97.2 \%$ of the in-person participants and $50.5 \%$ of the telephone participants had an informant.

\section{Clinical Characteristics of the Sample}

The most common diseases present at baseline were hypertension (79.9\%), cancer (35.3\%) and coronary heart disease (33.5\%, table 2). Stroke, atrial fibrillation and diabetes were present in nearly $20 \%$ of the sample. The frequency of coronary heart disease, diabetes, atrial fibrillation and cancer was higher in men than in women (table 2). In addition, $4.0 \%(n=42)$ of the men and $3.8 \%$ $(n=38)$ of the women were current smokers and $57.3 \%$ $(n=601)$ of the men and $32.2 \%(n=323)$ of the women were former smokers; $38.2 \%(n=397)$ of the men and $63.8 \%(n=635)$ of the women were never-smokers ( 8 men and 6 women did not report information on smoking). Systolic blood pressure was similar in men (median = 135 ; interquartile range $=122-148$ ) and in women (median $=137$; interquartile range $=124-150$ ), as was dia- stolic blood pressure $($ median $=71$, interquartile range $=$ $64-79$ in men; median $=70$, interquartile range $=62-78$ in women) and body mass index (median $=27.4$, interquartile range $=25.0-30.1$ in men; median $=26.8$, interquartile range $=23.4-30.6$ in women).

\section{Neuropsychological Assessments, TICS-m and AD8 Interviews}

Overall, men appeared to perform worse than women on certain cognitive tests. The median scores were slightly worse for men compared to women for Logical Memory II ( $p=0.009)$, Visual Reproduction II $(p=0.08)$, Auditory Verbal Learning Test percent recall $(p<0.001)$, Digit Symbol Substitution $(\mathrm{p}<0.001)$ and Category Fluency ( $p<0.001)$, but men performed slightly better than women in the Boston Naming Test $(\mathrm{p}<0.001)$, Picture Completion $(\mathrm{p}<0.001)$ and Block Design $(\mathrm{p}<0.001$; table 3). In general, performance was better in younger than in older subjects.

The distributions of the CDR sum of boxes, Functional Assessment Questionnaire and AD8 scores (for telephone participants) were positively skewed. For these measures, higher scores indicate greater impairment. Because there were no significant sex differences, the data below are for both sexes combined. The CDR sum of box-
64

Neuroepidemiology 2008;30:58-69
Roberts et al. 
Table 2. Clinical characteristics of in-person and telephone participants

\begin{tabular}{|c|c|c|c|c|c|c|c|c|c|c|c|c|}
\hline \multirow[t]{3}{*}{ Characteristic } & \multicolumn{5}{|c|}{ In-person participants } & \multicolumn{5}{|c|}{ Telephone participants } & \multirow{2}{*}{\multicolumn{2}{|c|}{$\begin{array}{l}\text { Total sample } \\
(\mathrm{n}=2,685)\end{array}$}} \\
\hline & \multicolumn{2}{|c|}{$\begin{array}{l}\text { men } \\
(\mathrm{n}=1,048)\end{array}$} & \multicolumn{2}{|c|}{$\begin{array}{l}\text { women } \\
(\mathrm{n}=1,002)\end{array}$} & \multirow{2}{*}{$\begin{array}{l}\text { all } \\
\%\end{array}$} & \multicolumn{2}{|c|}{$\begin{array}{l}\text { men } \\
(n=189)\end{array}$} & \multicolumn{2}{|c|}{$\begin{array}{l}\text { women } \\
(\mathrm{n}=446)\end{array}$} & \multirow{2}{*}{$\begin{array}{l}\text { all } \\
\%\end{array}$} & & \\
\hline & $\mathrm{n}$ & $\%$ & $\mathrm{n}$ & $\%$ & & $\mathrm{n}$ & $\%$ & $\mathrm{n}$ & $\%$ & & $\mathrm{n}$ & $\%$ \\
\hline Coronary heart disease & 459 & 43.8 & 239 & 23.9 & 34.0 & 86 & 45.5 & 115 & 25.8 & 31.7 & 899 & 33.5 \\
\hline Myocardial infarction & 216 & 20.6 & 103 & 10.3 & 15.6 & 48 & 25.4 & 52 & 11.7 & 15.7 & 419 & 15.6 \\
\hline Angina & 307 & 29.3 & 165 & 16.5 & 23.0 & 55 & 29.1 & 82 & 18.4 & 21.6 & 609 & 22.7 \\
\hline Coronary revascularization & 335 & 32.0 & 123 & 12.3 & 22.3 & 66 & 34.9 & 58 & 13.0 & 19.5 & 582 & 21.7 \\
\hline Diabetes & 217 & 20.7 & 167 & 16.7 & 18.7 & 50 & 26.5 & 90 & 20.2 & 22.0 & 524 & 19.5 \\
\hline Hypertension & 823 & 78.5 & 805 & 80.3 & 79.4 & 142 & 75.1 & 374 & 83.9 & 81.3 & 2,144 & 79.9 \\
\hline Atrial fibrillation & 205 & 19.6 & 123 & 12.3 & 16.0 & 43 & 22.8 & 77 & 17.3 & 18.9 & 448 & 16.7 \\
\hline Stroke & 161 & 15.4 & 132 & 13.2 & 14.3 & 30 & 15.9 & 75 & 16.8 & 16.5 & 398 & 14.8 \\
\hline Cancer & 464 & 44.3 & 284 & 28.3 & 36.5 & 83 & 43.9 & 117 & 26.2 & 31.5 & 948 & 35.3 \\
\hline
\end{tabular}

Characteristic: ascertained electronically from the medical diagnostic index using the Rochester Epidemiology Project medical records-linkage; 34 telephone participants who did not give permission to use their data were excluded. Coronary heart disease: subcategories are not mutually exclusive. Coronary revascularization includes coronary artery bypass grafting and percutaneous coronary interventions.

es had a median $=0$ (interquartile range $=0-0)$ for 70 - to 79 -year-olds and a median $=0$ (interquartile range $=0$ $0.5)$ for 80 - to 89 -year-olds. The Functional Assessment Questionnaire had a median $=0$ for both age groups (interquartile range $=0-1$ in 70 - to 79 -year-olds; interquartile range $=0-2$ in 80 - to 89 -year-olds). The AD8 median was 0 in 70 - to 79 -year-olds and in 80 - to 89 -year-olds (interquartile range $=0-1$ in 70 - to 79 -year-olds; interquartile range $=0-2$ in 80 - 89-year-olds). The TICS-m median was 33 (interquartile range $=31-36$ ) for 70 - to 79 year-olds and 31 (interquartile range $=27-35$ ) for 80 - to 89-year-olds.

\section{Comparison of Participants and Nonparticipants}

Participation in the study either in person or via telephone among the nondemented subjects (excluding subjects previously diagnosed as having dementia) decreased with increasing age: $68.1 \%(703 / 1,033)$ in 70 - to 79 -yearold women and $67.7 \%(730 / 1,078)$ in 70 - to 79 -year-old men compared to $57.6 \%(769 / 1,335)$ in 80 - to 89 -year-old women and $54.3 \%(517 / 952)$ in 80 - to 89 -year-old men. In multivariable logistic regression models adjusted for age, sex and education (where applicable), we observed greater participation among subjects with $>12$ years of education compared with $\leq 12$ years $(\mathrm{OR}=1.59,95 \% \mathrm{CI}=1.39$ 1.82). However, we found lower participation for subjects aged 80-89 years compared with those aged $70-79$ years $(\mathrm{OR}=0.56,95 \% \mathrm{CI}=0.49-0.64)$, for men compared with women $(\mathrm{OR}=0.86,95 \% \mathrm{CI}=0.75-0.98)$, for subjects with a Charlson Index of $\geq 3(\mathrm{OR}=0.74,95 \% \mathrm{CI}=0.64-0.85)$ or for subjects with a history of diabetes $(\mathrm{OR}=0.79,95 \%$ $\mathrm{CI}=0.68-0.93)$. History of stroke, marital status, hypertension, coronary heart disease and a previous diagnosis of MCI or dementia were not associated with the likelihood of participation (data not shown).

\section{Interrater Agreement of MCI Diagnosis}

Of the 329 subjects with MCI, there was perfect agreement on the diagnosis from all 3 components of the assessment in 233 (70.8\%) subjects (nurse evaluation, neurological evaluation and neuropsychological evaluation). By contrast, in 96 subjects (29.2\%), there was some discordance across the 3 components. The stability of the diagnosis will be evaluated during follow-up examinations by assessing the proportion of subjects with a baseline diagnosis of MCI who have a later diagnosis of normal cognition, stable MCI or dementia.

\section{Conclusions}

The Mayo Clinic Study of Aging is a prospective population-based cohort study of normal cognitive aging, MCI and dementia. Our experience showed that elderly subjects who are unwilling to participate in an in-person research evaluation may be willing to participate by tele- 
Table 3. Results of neuropsychological assessments for in-person participants by age and sex

\begin{tabular}{|c|c|c|c|}
\hline \multirow[t]{2}{*}{ Measurement (test range) } & \multicolumn{3}{|c|}{ Median score (LE, Q1, Q3, UE) } \\
\hline & $\begin{array}{l}\text { men } \\
(\mathrm{n}=1,048)\end{array}$ & $\begin{array}{l}\text { women } \\
(\mathrm{n}=1,002)\end{array}$ & $\begin{array}{l}\text { all } \\
(\mathrm{n}=2,050)\end{array}$ \\
\hline \multicolumn{4}{|l|}{ Logical Memory II (0-50) } \\
\hline $70-79$ years & $14(0,9,20,37)$ & $16(0,10,22,38)$ & $15(0,10,21,38)$ \\
\hline $80-89$ years & $11(0,6,17,35)$ & $13(0,8,18,36)$ & $12(0,7,18,36)$ \\
\hline \multicolumn{4}{|c|}{ Visual Reproduction II (0-41) } \\
\hline $70-79$ years & $19(0,11,26,40)$ & $20(0,13,26,37)$ & $19(0,12,26,40)$ \\
\hline $80-89$ years & $11(0,6,19,38)$ & $13(0,7,21,37)$ & $12(0,7,20,38)$ \\
\hline \multicolumn{4}{|c|}{ AVLT percent delayed recall (0-100\%) } \\
\hline $70-79$ years & $67(0,44,83,100)$ & $78(0,63,90,100)$ & $73(0,55,86,100)$ \\
\hline $80-89$ years & $57(0,29,80,100)$ & $73(0,55,89,100)$ & $67(0,44,85,100)$ \\
\hline \multicolumn{4}{|c|}{ Digit Symbol Substitution (0-93) } \\
\hline $70-79$ years & $39(3,32,45,68)$ & $45(16,38,52,70)$ & $42(3,35,48,70)$ \\
\hline $80-89$ years & $32(5,26,38,59)$ & $36(10,29,43,73)$ & $34(5,27,41,73)$ \\
\hline \multicolumn{4}{|l|}{ Trail Making Test B (0-300) } \\
\hline $70-79$ years & $102(30,81,137,300)$ & $99.5(40,78,134,300)$ & $101(30,79,136,300)$ \\
\hline $80-89$ years & $143.5(38,100,208,300)$ & $134(42,101,197,300)$ & $139(38,100,203.5,300)$ \\
\hline \multicolumn{4}{|l|}{ Boston Naming Test $(0-60)$} \\
\hline $70-79$ years & $55(16,52,58,60)$ & $55(27,51,57,60)$ & $55(16,51,57,60)$ \\
\hline $80-89$ years & $54(17,48,57,60)$ & $51(21,47,55,60)$ & $52(17,47,56,60)$ \\
\hline \multicolumn{4}{|l|}{ Category Fluency (unlimited) } \\
\hline $70-79$ years & $39(11,33,44,65)$ & $45(18,38,51,78)$ & $41(11,35,49,78)$ \\
\hline $80-89$ years & $36(8,30,42,60)$ & $39(13,33,45,67)$ & $37(8,31,43,67)$ \\
\hline \multicolumn{4}{|l|}{ Picture Completion $(0-20)$} \\
\hline $70-79$ years & $13(1,12,15,19)$ & $13(2,10,15,19)$ & $13(1,11,15,19)$ \\
\hline $80-89$ years & $12(0,10,14,19)$ & $11(0,8,13,19)$ & $11(0,9,13,19)$ \\
\hline \multicolumn{4}{|l|}{ Block Design (0-51) } \\
\hline $70-79$ years & $24(0,18,30,49)$ & $22(1,17,27,47)$ & $23(0,18,29,49)$ \\
\hline $80-89$ years & $19(0,14,25,41)$ & $19(0,12,23,42)$ & $19(0,13,24,42)$ \\
\hline \multicolumn{4}{|c|}{ Short Test of Mental Status (0-38) } \\
\hline $70-79$ years & $34(9,32,36,38)$ & $34(14,32,36,38)$ & $34(9,32,36,38)$ \\
\hline $80-89$ years & $32(10,30,35,38)$ & $33(8,31,35,38)$ & $33(8,30,35,38)$ \\
\hline
\end{tabular}

Higher Trail Making Test B scores mean greater impairment; for the other measures, lower scores mean greater impairment. Median = 50th percentile; LE = lower extreme; Q1 = 25th percentile; Q3 = 75th percentile; UE = upper extreme; AVLT = Auditory Verbal Learning Test.

phone. The paper also describes the frequency of vascular risk factors and neuropsychological characteristics in a population-based sample. The frequency of vascular risk factors was higher in men compared to women. The neuropsychological assessments demonstrated slightly worse performance in men than in women. These findings may have implications for interpreting sex differences in MCI prevalence at baseline and in incidence of MCI and dementia during follow-up.

The use of the TICS-m and the AD8 (administered to an informant) in telephone participants provided insights on the cognitive and functional status of subjects who did not accept the in-person evaluation. Although we may be unable to directly assess MCI in these subjects using the same criteria as used for in-person participants, we will be able to assess cognitive and functional decline from changes in the TICS-m and the AD8 during followup. We will also be able to passively ascertain incident dementia during follow-up using information from the medical records-linkage system.

\section{Strengths of the Present Study}

There are several strengths of the study. We will estimate the prevalence of MCI in a geographically-defined population. In addition, follow-up of the cohort will enable us to estimate the incidence of MCI and dementia, to
66

Neuroepidemiology 2008;30:58-69
Roberts et al. 
estimate the rate of progression from MCI to dementia and to investigate predictors of conversion from normal cognition to MCI or from MCI to dementia. The population-based design minimizes potential referral bias and enhances the generalizability of the study findings. In contrast, subjects recruited from memory clinics have more advanced memory-related disease and a narrower spectrum of cognitive impairment, resulting in potentially biased findings. The study is also free from biases due to the use of volunteer samples recruited via advertisement or via referral to specialized centers. Volunteers may participate because of a known family history of the condition under study or may have greater health awareness leading to biased findings.

The prevalence estimates for MCI will be determined from the entire sample of in-person participants identified without a staged screening procedure. This is important because the diagnosis of MCI is subtle and is most accurate through an extensive in-person evaluation. A unique strength of the study is that it merges the strengths of a population-based design with the clinical expertise of the study personnel. Additionally, baseline information on vascular risk factors and magnetic resonance imaging measurements will be useful for longitudinal studies of risk factors. Stored DNA, plasma and serum samples are available to identify biomarkers for MCI risk and progression. Another strength of the study is that the diagnoses of MCI, dementia or normal cognition were based on published criteria; however, they also reflected clinical judgment and a consensus panel.

Another strength of the study is that we are able to describe the characteristics and clinical outcomes in nonparticipants. Through the medical records-linkage system, we have access to the medical records of subjects who did not participate in the in-person examination; $98 \%$ of the nonparticipants have provided authorization for use of their medical records in research. Therefore, we can describe their clinical comorbidities and cognitive characteristics at baseline and will be able to passively follow them through the medical records to ascertain dementia outcomes noted as part of their routine medical care.

\section{Potential Limitations of the Present Study}

There are potential limitations to our study. Elderly persons are typically less inclined to participate in studies that assess cognition, and this may have limited participation in the study. Our participation of $62 \%$ was comparable with reported estimates of about $67 \%$ in the Framingham Heart Study [47], 64\% in the Honolulu Asia Ag- ing Study [48], 63\% in the Rotterdam Scan Study [49], $62 \%$ in the Washington Heights-Inwood Study [50] and in other studies [51-54]. However, the participation experienced in our study was slightly lower than $78 \%$ or higher reported from other studies [55, 56]. Given the complexities of recruitment in the current era, including institutional review board requirements and the need for HIPAA authorization, it is more difficult to recruit subjects to population-based studies, and our participation rates appear reasonable. A comparison of participants and nonparticipants (using the medical records-linkage system data) showed a slightly higher prevalence of comorbid conditions among nonparticipants. Passive follow-up of nonparticipants using the medical recordslinkage system and active follow-up of participants will enable us to compare the incidence of dementia in the 2 groups. Unfortunately, MCI is not typically assessed in routine patient care; thus, it may be more difficult to determine any differences in the incidence of MCI. Finally, because only $1.4 \%$ of the subjects in our sample were nonCaucasians, we cannot perform meaningful subgroup analyses by ethnicity. Nonetheless, the findings from this study will be useful for comparison with studies in other ethnicities.

\section{Acknowledgments}

This work is supported by grants from the National Institute on Aging (P50 AG16574 and U01 AG06786), the National Institute of Mental Health (K01 MH68351), the National Institute of Aging (K01 AG028573), the National Institute of Arthritis and Musculoskeletal and Skin Diseases (R01 AR30582), and by the Robert H. and Clarice Smith and Abigail van Buren Alzheimer's Disease Research Program.

References $\nabla_{1}$ Jorm AF, Korten AE, Henderson AS: The prevalence of dementia: a quantitative integration of the literature. Acta Psychiatr Scand 1987;76:465-479.

2 Kukull WA, Ganguli M: Epidemiology of dementia: concepts and overview. Neurol Clin 2000;18:923-950.

3 Fratiglioni L, Rocca WA: Epidemiology of dementia; in Boller F, Cappa S (eds): Handbook of Neuropsychology. Amsterdam, Elsevier, 2001, vol 6, pp 193-215.

-4 Bachman DL, Wolf PA, Linn RT, Knoefel JE, Cobb JL, Belanger AJ, White LR, D’Agostino RB: Incidence of dementia and probable Alzheimer's disease in a general population: The Framingham Study. Neurology 1993;43: 515-519. 
5 Hebert LE, Scherr PA, Beckett LA, Albert MS, Pilgrim DM, Chown MJ, Funkenstein $\mathrm{HH}$, Evans DA: Age-specific incidence of Alzheimer's disease in a community population. JAMA 1995;273:1354-1359.

6 Petersen RC: Mild cognitive impairment as a diagnostic entity. J Intern Med 2004;256: 183-194.

7 Melton LJ III: History of the Rochester Epidemiology Project. Mayo Clin Proc 1996;71: 266-274.

8 Bergstralh EJ, Offord KP: Projected Rochester and Olmsted County Populations for 1981-1995. Technical Report Series No 38. Rochester, Section of Biostatistics, Mayo Clinic, 1988.

$\checkmark 9$ Beard CM, Kokmen E, Offord K, Kurland LT: Is the prevalence of dementia changing? Neurology 1991;41:1911-1914.

-10 Beard CM, Kokmen E, O’Brien PC, Kurland LT: The prevalence of dementia is changing over time in Rochester, Minnesota. Neurology 1995;45:75-79.

-11 Kokmen E, Beard CM, Offord KP, Kurland LT: Prevalence of medically diagnosed dementia in a defined United States population: Rochester, Minnesota, January 1, 1975. Neurology 1989;39:773-776.

-12 Lopez OL, Jagust WJ, DeKosky ST, Becker JT, Fitzpatrick A, Dulberg C, Breitner J, Lyketsos C, Jones B, Kawas C, Carlson M, Kuller LH: Prevalence and classification of mild cognitive impairment in the Cardiovascular Health Study Cognition Study: part 1. Arch Neurol 2003;60:1385-1389.

13 McMurry M: Minnesota Life Expectancy in 2000. St Paul, Minnesota Planning State Demographic Center, 2002.

- 14 Stampfer MJ, Krauss RM, Ma J, Blanche PJ, Holl LG, Sacks FM, Hennekens CH: A prospective study of triglyceride level, low-density lipoprotein particle diameter, and risk of myocardial infarction. JAMA 1996;276: 882-888.

-15 Desmeules S, Arcand-Bosse JF, Bergeron J, Douville P, Agharazii M: Nonfasting nonhigh-density lipoprotein cholesterol is adequate for lipid management in hemodialysis patients. Am J Kidney Dis 2005;45:10671072.

-16 Spitzer RL, Williams JB, Kroenke K, Linzer M, deGruy FV 3rd, Hahn SR, Brody D, Johnson JG: Utility of a new procedure for diagnosing mental disorders in primary care: the PRIME-MD 1000 study. JAMA 1994;272: 1749-1756.

17 Beck AT, Steer RA, Brown GK: Manual for Beck Depression Inventory-II (BDI-II). San Antonio, Psychology Corporation, 2001.

18 Beck AT, Steer RA: Beck Anxiety Inventory Manual. San Antonio, Psychological Corporation, 1993.
19 Cesari M, Kritchevsky SB, Penninx BW, Nicklas BJ, Simonsick EM, Newman AB, Tylavsky FA, Brach JS, Satterfield S, Bauer DC, Visser M, Rubin SM, Harris TB, Pahor M: Prognostic value of usual gait speed in wellfunctioning older people - results from the Health, Aging and Body Composition Study. J Am Geriatr Soc 2005;53:1675-1680.

20 Morris JC: The Clinical Dementia Rating (CDR): current version and scoring rules. Neurology 1993;43:2412-2414.

21 Pfeffer RI, Kurosaki TT, Harrah CH Jr, Chance JM, Filos S: Measurement of functional activities in older adults in the community. J Gerontol 1982;37:323-329.

22 Kokmen E, Smith GE, Petersen RC, Tangalos E, Ivnik RC: The short test of mental status: correlations with standardized psychometric testing. Arch Neurol 1991;48:725-728.

23 Rosen WG, Terry RD, Fuld PA, Katzman R, Peck A: Pathological verification of ischemic score in differentiation of dementias. Ann Neurol 1980;7:486-488.

24 Hachinski VC, Iliff LD, Zilhka E, Du Boulay GH, McAllister VL, Marshall J, Russell RW, Symon L: Cerebral blood flow in dementia. Arch Neurol 1975;32:632-637.

25 American Psychiatric Association: Diagnostic and Statistical Manual of Mental Disorders (DSM-IV), ed 4. Washington, American Psychiatric Association, 1994.

26 Fahn S, Elton RL, UPDRS Development Committee: Unified Parkinson's Disease Rating Scale; in Fahn S, Marsden CD, Calne DB, Goldstein M (eds): Recent Developments in Parkinson's Disease. Florham Park, MacMillan Healthcare Information, 1987, vol 2, pp 153-163.

27 Wechsler DA: Wechsler Adult Intelligence Scale-Revised. New York, Psychological Corporation, 1987.

28 Wechsler DA: Wechsler Memory Scale-Revised. New York, Psychological Corporation, 1987.

29 Reitan RM: Validity of the Trail Making Test as an indicator of organic brain damage. Percept Motor Skills 1958;8:271-276.

30 Kaplan EF, Goodglass H, Weintraub S: The Boston Naming Test, ed 2. Philadelphia, Lea \& Febiger, 1982.

31 Lucas JA, Ivnik RJ, Smith GE, Bohac DL, Tangalos EG, Graff-Radford NR, Petersen RC: Mayo's Older Americans Normative Studies: category fluency norms. J Clin Exp Neuropsychol 1998;20:194-200.

32 Ivnik RJ, Malec JF, Smith GE, et al: WAISR, WMS-R and AVLT norms for ages 56 through 97. Clin Neuropsychol 1992;6 (suppl):1-104.

33 Ivnik RJ, Malec JF, Smith GE, Tangalos EG, Petersen RC: Neuropsychological tests' normal above age 55: COWAT, BNT, MAE token, WRAT-RReading, AMNART, STROOP, MT, and JLO. Clin Neuropsychol 1996;10: $262-278$.
34 Ivnik RJ, Smith GE, Lucas JA, Petersen RC, Boeve BF, Kokmen E, Tangalos EG: Testing normal older people three or four times at 1to 2-year intervals: defining normal variance. Neuropsychology 1999;13:121-127.

35 Brandt J, Spencer M, Folstein M: The telephone interview for cognitive status. Neuropsychiatry Neuropsychol Behav Neurol 1988;1:111-117.

36 Welsh KA, Breitner JCS, Magruder-Habib KM: Detection of dementia in the elderly using telephone screening of cognitive status. Neuropsychiatry Neuropsychol Behav Neurol 1993;6:103-110.

37 Plassman BL, Newman TT, Welsh KA, Helms M, Breitner JCS: Properties of the telephone interview for cognitive status: application in epidemiological and longitudinal studies. Neuropsychiatry Neuropsychol Behav Neurol 1994;7:235-241.

38 Crooks VC, Clark L, Petitti DB, Chui H, Chiu V: Validation of multi-stage telephone-based identification of cognitive impairment and dementia. BMC Neurol 2005;5:8.

39 Galvin JE, Roe CM, Powlishta KK, Coats MA, Muich SJ, Grant E, Miller JP, Storandt M, Morris JC: The AD8: a brief informant interview to detect dementia. Neurology 2005;65:559-564.

40 Galvin JE, Roe CM, Coats MA, Morris JC: Patient's rating of cognitive ability: using the AD8, a brief informant interview, as a selfrating tool to detect dementia. Arch Neurol 2007;64:725-730.

41 Fried LP, Borhani NO, Enright P, Furberg CD, Gardin JM, Kronmal RA, Kuller LH, Manolio TA, Mittelmark MB, Newman A, et al: The Cardiovascular Health Study: design and rationale. Ann Epidemiol 1991;1:263276.

42 ARIC investigators: The Atherosclerosis Risk in Communities (ARIC) Study: design and objectives. Am J Epidemiol 1989;129: 687-702.

43 Centers for Disease Control and Prevention (CDC): Behavioral Risk Factors Surveillance System Survey Questionnaire. Atlanta, US Department of Health and Human Services, Centers for Disease Control and Prevention, 2004.

44 St Sauver JL, Hagen PT, Cha SS, Bagniewski SM, Mandrekar JN, Curoe AM, Rodeheffer RJ, Roger VL, Jacobsen SJ: Agreement between patient reports of cardiovascular disease and patient medical records. Mayo Clin Proc 2005; 80:203-210.

45 Maradit-Kremers H, Nicola PJ, Crowson CS, Ballman KV, Gabriel SE: Cardiovascular death in rheumatoid arthritis: a populationbased study. Arthritis Rheum 2005;52:722732. 
46 Charlson ME, Pompei P, Ales KL, MacKenzie CR: A new method of classifying prognostic comorbidity in longitudinal studies: development and validation. J Chron Dis 1987;40:373-383.

47 Elias MF, Elias PK, Sullivan LM, Wolf PA, D'Agostino RB: Lower cognitive function in the presence of obesity and hypertension: the Framingham Heart Study. Int J Obes Relat Metab Disord 2003;27:260-268.

$\checkmark 48$ White L, Petrovitch H, Ross GW, Masaki $\mathrm{KH}$, Abbott RD, Teng EL, Rodriguez BL, Blanchette PL, Havlik RJ, Wergowske G, Chiu D, Foley DJ, Murdaugh C, Curb JD: Prevalence of dementia in older JapaneseAmerican men in Hawaii: The HonoluluAsia Aging Study. JAMA 1996;276:955-960.
9 De Groot JC, De Leeuw F-E, Oudkerk M, Van Gijn J, Hofman A, Jolles J, Breteler MMB: Cerebral white matter lesions and cognitive function: the Rotterdam Scan Study. Ann Neurol 2000;47:145-151.

50 Luchsinger JA, Tang MX, Shea S, Miller J, Green R, Mayeux R: Plasma homocysteine levels and risk of Alzheimer disease. Neurology 2004;62:1972-1976.

-51 Fischer P, Jungwirth S, Zehetmayer S, Weissgram S, Hoenigschnabl S, Gelpi E, Krampla $\mathrm{W}$, Tragl KH: Conversion from subtypes of mild cognitive impairment to Alzheimer dementia. Neurology 2007;68:288-291.

52 Bennett DA, Schneider JA, Buchman AS, Mendes de Leon C, Bienias JL, Wilson RS: The Rush Memory and Aging Project: study design and baseline characteristics of the study cohort. Neuroepidemiology 2005;25: 163-175.
3 Tell GS, Fried LP, Hermanson B, Manolio TA, Newman AB, Borhani NO: Recruitment of adults 65 years and older as participants in The Cardiovascular Health Study. Ann Epidemiol 1993;3:358-366.

54 Ganguli M, Dodge HH, Shen C, DeKosky ST: Mild cognitive impairment, amnestic type: an epidemiologic study. Neurology 2004;63: 115-121.

55 Guo Z, Viitanen M, Fratiglioni L, Winblad B: Low blood pressure and dementia in elderly people: the Kungsholmen project. BMJ 1996; 312:805-808.

56 Breitner JC, Wyse BW, Anthony JC, WelshBohmer KA, Steffens DC, Norton MC, Tschanz JT, Plassman BL, Meyer MR, Skoog I, Khachaturian A: APOE- $\varepsilon 4$ count predicts age when prevalence of $\mathrm{AD}$ increases, then declines: the Cache County Study. Neurology $1999 ; 53: 321-331$. 